\title{
The influence of packaging design features on consumers’ purchasing \& recycling behaviour
}

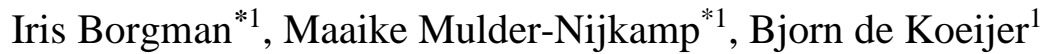 \\ 1 Department of Design, Production and Management, Faculty of Engineering Technology, \\ University of Twente. Drienerlolaan 5, 7522 NB Enschede, The Netherlands
}

\begin{abstract}
This paper describes an empirical study to determine the influence of specific design elements of sustainable packaging on consumer behaviour during purchase and recycling. Existing studies show that the visual appearance of packaging design influences the behaviour of consumers. The results of this study show that decisions made by consumers regarding the packaging are mostly based on graphics and to a lesser extent on information and form. Furthermore, a sustainable form and information regarding sustainability also have the highest utility, which indicates that these cues are able to trigger a higher buying intention. According the results on recycling behaviour, it is unclear if recycling logos and a stimulating text have an impact on recycling intention of consumers.
\end{abstract}

Keywords: packaging design, packaging development, sustainability, purchase behaviour, recycling behaviour, marketing.

\section{Introduction}

Consumers open, on average, more than seven packages a day (Crowe, 2003) which are usually thrown away directly after use. Consequently, packaging waste has become a symbol of the throwaway society (Anonymous, 2013), unavoidably adding to our environmental impact (Magnier \& Schoormans, 2015). Therefore, it is logical for companies to introduce sustainable packages (Magnier \& Schoormans, 2015). Besides environmental concern, this causes financial and strategic rewards as efficient production lowers costs and leads to profitability (QuadPackaging, 2018). Within this trend consumers are very important actors. The visual appearance of a package has great influence on their behaviour during (1) the processes of making conscious sustainable purchasing decisions and (2) sorting packaging waste after usage. Regarding purchase, consumers evaluate packaging as positive when it contains elements that communicate eco-friendliness. However, only a few studies specifically focus on the influence of those design elements on consumer behaviour (Magnier \& Crie, 2015; Steenis, Van Herpen, van der Lans, Ligthart, \& van Trijp, 2017). According to these studies product choice is clearly influenced by environmental aspects of the packaging (Magnier \& Crie, 2015; Rokka \& Uusitalo, 2008) but it is not clarified how these aspects influence their behaviour and how packaging designers should use this knowledge.

${ }^{*}$ Correspondence to: Iris Borgman, University of Twente, Enschede, The Netherlands. E-mail: i.m.borgman@student.utwente.nl. Maaike Mulder-Nijkamp, University of Twente, Enschede, The Netherlands. E-mail: m.mulder-nijkamp@utwente.nl 
Regarding the recycling process, prior research has mainly focused on recycling habits of consumers and to a lesser extent on the link between consumer behaviour and packaging design. However, the design can have an important influence on how a package is sorted and eventually processed (Buelow, Lewis, \& Sonneveld, 2010). Herein we want to focus again on the influence of specific design elements.

This paper aims to bridge the gap between packaging design and consumer behaviour during purchase and recycling of sustainable packaging. We specifically aim to seek knowledge which is applicable for designers. A theoretical analysis provides an overview of current literature combining behavioural sciences with design research. Since purchasing and recycling are separate processes, the former process is discussed first followed by the latter. Based on (the gaps in) the literature, combinations of design elements are analysed with a conjoint analysis which provides more in-depth research into specific elements of the design. The most effective elements are integrated into packaging designs which are tested by consumers in a realistic setting, providing insight in more realistic purchasing and recycling behaviour. A comparable test setup has not yet been conducted among existing studies on this subject.

\section{Combining Design Research with Behavioural Research}

According to literature on purchase behaviour consumers lack knowledge on the concept of sustainability (Lindh, Olsson, \& Williams, 2016; Nordin \& Selke, 2010; Steenis et al., 2017). They find it difficult to differentiate between sustainable and non-sustainable packaging, since it is almost impossible for them to determine the environmental status of a package(Magnier \& Schoormans, 2015). Their judgements regarding the sustainability of the packaging are clearly dominated by material-related considerations (Lindh et al., 2016; Magnier \& Schoormans, 2015; Steenis et al., 2017; Young, 2008). One of the key challenges for packaging designers is to design sustainable packaging that is acceptable to consumers, while considering that the levels of sustainability for consumers are not always aligned with actual sustainability of the materials (Steenis et al., 2017). This stresses the importance that packaging communicates an understandable and reliable message with regard to environmental issues and clearly signals it is sustainable (Jerzyk, 2016; Magnier \& Schoormans, 2015). Studies have found packaging features which convey eco-friendliness in consumers' opinions based on three attributes of the packaging: form/structure, graphics and on-package information. This is shown in Table 1(Magnier \& Crie, 2015). While using such environmental cues, it is important to maintain congruency between for instance a verbal claim and the graphical design, otherwise it may lead to perceived greenwashing. If a package has an ecological look, verbal sustainability claims can highlight certain visual elements in order to increase its persuasive impact (Magnier \& Schoormans, 2015).

Table 1: Packaging features that convey eco-friendliness

\begin{tabular}{|l|l|l|l|}
\hline Structure/form & Less material & Recycled/recyclable materials & Reusable package \\
\hline Graphics & Brown, green, white & Nature imagery & \\
\hline Information & Environmental claims & Environmental logos & $\begin{array}{l}\text { Labels from environmental } \\
\text { organisations }\end{array}$ \\
\hline
\end{tabular}

Regarding literature on recycling behaviour attributes of the packaging design are used to promote or influence recycling behaviour. Among these attributes labels, such as recycling 
symbols, are the most common approach to increase consumers' recycling behaviour(Buelow et al., 2010). This information alone however, does not necessarily translate into actual recycling(Geiger, Ünal, Van der Werff, \& Steg, forthcoming; Pancer, McShane, \& Noseworthy, 2015). Also, the link between sustainable packaging and recycling behaviour is critical since perceived sustainability is a mediator of recycling behaviour. In other words, a packaging has to be perceived as sustainable by an individual before being willing to recycle it (Geiger et al., forthcoming; Ruepert, Keizer, \& Steg, 2017).

To summarise, all studies show that the visual appearance of packaging design influences the behaviour of consumers. We are searching for a link between design and behaviour and more specifically looking at the role of several cues aimed at purchase intention and recycling behaviour. Thus providing packaging designers with applicable information to work with.

\section{Methods}

We conducted an empirical study to determine the influence of the design of sustainable packaging on purchasing and recycling behaviour. The study was split into three parts: a prestudy and two main parts. Part one focused on the influence of packaging features on several factors related to purchase and recycling intention. In order to determine the stimuli for this study, a pre-study was performed. Part two used the outcomes of part one to test purchasing and recycling intention in a realistic supermarket setting.

\subsection{Pre-study}

At first, we conducted a qualitative pre-study among a small group of 20 respondents (55\% female, $\mathbf{M}_{\text {age }}=26.7$ ) using an online ranking tool. The stimuli were composed by images of a bottle of water, which varied in three categories of packaging cues: the graphical design of the label (graphics), information or certification on sustainability (information) and the form and structure of the bottle (form). This to be able to analyse specific elements of the packaging design. For each of the three categories 8-10 designs were made based on packaging features which convey eco-friendliness among consumers (also see Table 1). For each category, a baseline design was chosen, which is based on existing water bottles and can be seen as conventional and recognizable. The other designs were meant to be more sustainable-looking, but this was not communicated to the respondents. To keep the designs identical and to prevent noise from other design aspects which are not meant to influence the results, only certain aspects of the packaging were manipulated for each category. The scheme of form let the bottle differ in overall shape and structure. Only the bottle itself was displayed without a label, since the placing and size is dependent on the form and variation can have an influence on the look and salience of the different designs. The graphics scheme of the label differed in colours, imagery and slightly in logo if this was necessary to remain a stable and good-looking design. In the information scheme, the bottles and label were identical for each design and information or certification was placed either on an additional label on the upper part of the bottle or added to the main label.

\subsubsection{Results and discussion pre-study}

Respondents ranked the three categories of designs twice, first according to buying intention and secondly according to sustainability perception. For each category the most sustainable and a 
neutral design were obtained. The latter was composed by the least sustainable features. Purchase intention was taken into account, meaning that the designs with the highest and lowest positions on sustainability, at least had an average buying intention to make sure that the full profile design is realistic in the sense that people are willing to buy it. Participants stated similar remarks about certain designs. In terms of the graphics, the colours green and brown and nature imagery were consistently perceived as sustainable. However, in the case of water bottles many participants claimed they would not associate the product in combination with green and especially not with brown. Rather they would expect the colour blue. This indicates that people expect a certain congruency between the packaging and its content (Van Rompay \& Pruyn, 2011). Simply designing a green or brown packaging will not work for every packaging as the combination with the product inside may cause confusion and lack of appeal. The pre-study resulted in the graphical, informational and form features for the most sustainable and a neutral design. These are shown in Figure 1.

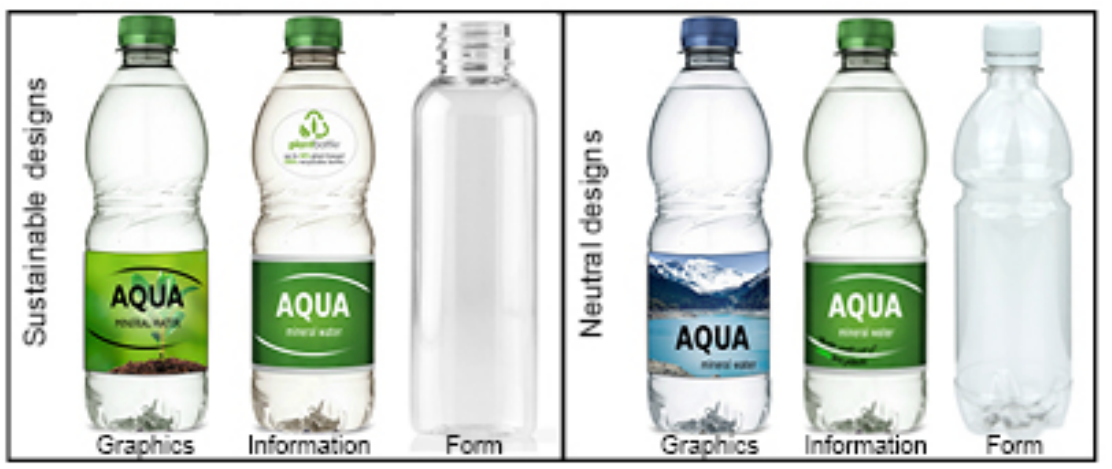

\subsection{Part one}

Figure 1: Resulting features of the graphics, information and form scheme

A full profile conjoint analysis was conducted to identify which of the resulting features from the pre-study were dominant. For each of the three factors (graphics, information, form) were two possibilities: a sustainable and a neutral design. This resulted in a 2x2x2 conjoint design with eight profiles as shown in Figure 2.

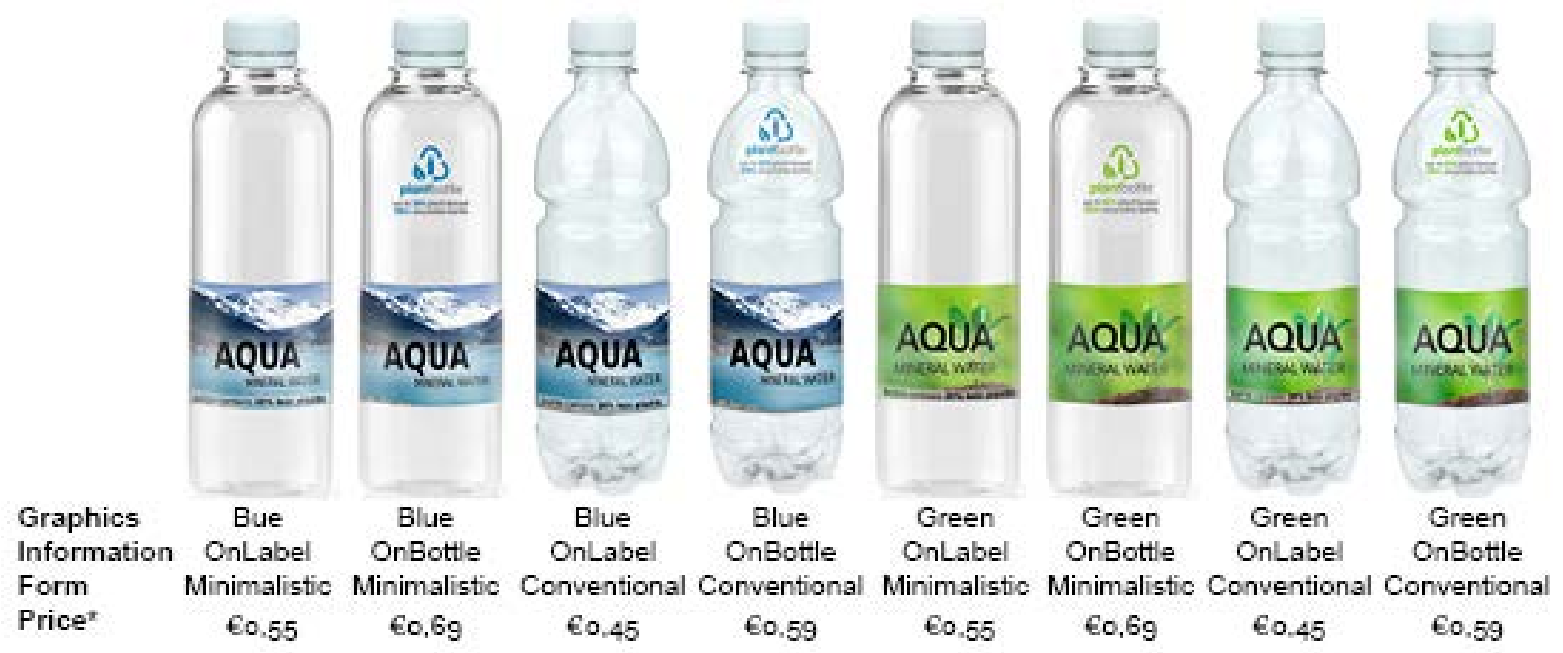

Figure 2: Designs for the conjoint analysis

*Prices are only included in the second last question of the survey 
The full profiles were used in an online survey where the main part consisted of five rankings of the eight bottles, each based on different subjects: buying intention, recycling intention, appeal, reliability of the producer and sustainability. Respondents were asked to rank the bottles from one to eight, with one the highest and eight the lowest. The following section requested respondents to choose which of the eight bottles they would most likely buy when the price was added and they were requested to indicate why. The last section contained a question where respondents had to allocate a total of 100 points to characteristics of a bottle of water, according to importance. These were the following characteristics: colour/design of the label, form/design of the bottle, sustainability of the bottle, price, reliability of the producer, recyclability and 'other' which could be filled in by the respondent. Each question in the survey was mandatory with exception of the explanation after the question which showed the bottles with prices added.

\subsection{Part two}

Part two of the study used the outcomes of the conjoint analysis to test buying intention (1) and recycling intention (2) among supermarket ${ }^{1}$ customers. The bottles with the highest and lowest utility according to the conjoint analysis were produced as physical bottle and we asked customers about their purchase intention based on those. We expected that the bottle with the highest utility would trigger the highest purchase intention. In order to test recycling intention, we handed out plastic cups filled with flavoured water and let customers taste the water. They were told where the bins were located but they did not receive an instruction to recycle the cups. The cups were filled with two variants of water with fresh ingredients: mint \& lime and mango \& orange. This allowed us to test two types of cues: one with recycling info and one without. The mint \& lime wrapper contained the text "recycle me" in Dutch along with logos from the 'Waste Pointer' 2 . The text stimulates to recycle and the logos show where the several parts of the packaging and waste should be thrown away. The wrappers are shown in Figure 3.

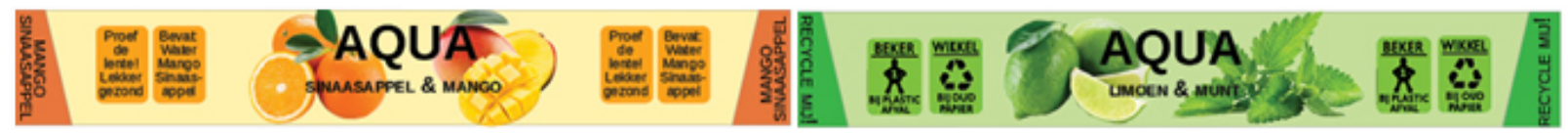

Figure 3: The orange wrapper resembles the green wrapper, but without recycling cues or logos. The green wrapper contains recycling logos at the left and right and extensions with the text 'recycle me'.

After consumption of the flavoured water, the wrapper had to be thrown into paper waste, any residue of the ingredients into organic waste and the cup into plastic waste. To facilitate this, a recycling bin with separate compartments for plastic, organic and residual waste and an extra conventional bin with one compartment for residual waste were located close to the stand. The extra bin was added, because with only a recycling bin, this may stimulate recycling intention already whereas the recycling intention should be stimulated by the packaging cues. After execution of the test, the bins were checked to indicate if the cups were discarded correctly and if there was any difference between the two designs. We expected that the recycling rates of the mint \& lime cups would be higher than those of the mango \& orange cups.

\footnotetext{
${ }^{1}$ The test was executed at an Albert Heijn supermarket in the city of Hengelo, The Netherlands.

${ }^{2}$ In the Netherlands the guideline 'Weggooiwijzer' (waste pointer) has been set up by the Netherlands Institute for Sustainable Packaging (KIDV) to help packaging producers with the application of logos which instruct consumers how to throw away their packaging.
} 


\section{Results and Discussion}

\subsection{Part one}

The survey was completed by 73 respondents (47,9\% female). The results of the rankings are partly presented in Table 2, showing the rankings on appeal and recycling intention. Many surveys were not finished by respondents, which might have been caused by the repetitive character of the rankings. However, the number of finished surveys is suitable to analyse the results. Furthermore, the outcomes of the survey are tested again during part two of the study which confirms the results. The correlations for all rankings are acceptable, as they show that predictions based on the conjoint analysis largely correlate with actual choices people make. For all rankings, the blue label and on-bottle information have the highest utility, which is according to our expectation. According to the rankings on recycling and reliability, the conventional form has the highest utility, whereas the minimalistic form has the highest utility for appeal, sustainability and buying intention. Figure 4 shows the mentioned designs.

Table 2: Utility scores of the features per ranking as well as the importance values of the factors (graphics, info and form)

\begin{tabular}{|c|c|c|c|c|c|c|c|}
\hline \multirow[b]{2}{*}{ Factor } & \multirow[b]{2}{*}{ Level } & \multicolumn{3}{|c|}{ Ranking appeal } & \multicolumn{3}{|c|}{ Ranking recycling } \\
\hline & & $\begin{array}{l}\text { Utility } \\
\text { estimate }\end{array}$ & $\begin{array}{l}\text { Std. } \\
\text { error }\end{array}$ & $\begin{array}{l}\text { Importance } \\
\text { values }\end{array}$ & $\begin{array}{l}\text { Utility } \\
\text { estimate }\end{array}$ & Std. error & $\begin{array}{l}\text { Importance } \\
\text { values }\end{array}$ \\
\hline \multirow[t]{2}{*}{ Graphics } & Green & 1.007 & 0.242 & \multirow[t]{2}{*}{39.453} & 0.541 & 0.229 & \multirow[t]{2}{*}{46.804} \\
\hline & Blue & 2.014 & 0.483 & & 1.082 & 0.459 & \\
\hline \multirow[t]{2}{*}{ Info } & OnLabel & 0.801 & 0.242 & \multirow[t]{2}{*}{30.573} & 0.712 & 0.229 & \multirow[t]{2}{*}{29.002} \\
\hline & OnBottle & 1.603 & 0.483 & & 1.425 & 0.459 & \\
\hline \multirow[t]{3}{*}{ Form } & Minimalistic & -0.219 & 0.242 & \multirow[t]{2}{*}{29.975} & 0.048 & 0.229 & \multirow[t]{2}{*}{24.194} \\
\hline & Conventional & $\begin{array}{l}-0.438 \\
\end{array}$ & 0.483 & & 0.096 & 0.459 & \\
\hline & Constant & 2.116 & 0.639 & & 2.548 & 0.607 & \\
\hline \multicolumn{2}{|c|}{ Correlations } & Value & Sig. & & Value & Sig. & \\
\hline \multicolumn{2}{|c|}{ Pearson's R } & 0.938 & 0.000 & & 0.890 & 0.002 & \\
\hline \multicolumn{2}{|c|}{ Kendall's tau } & 0.786 & 0.003 & & 0.714 & 0.007 & \\
\hline
\end{tabular}

1.

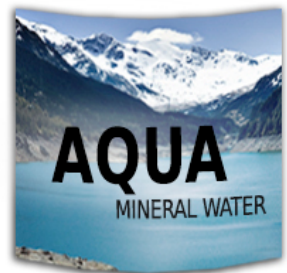

2.

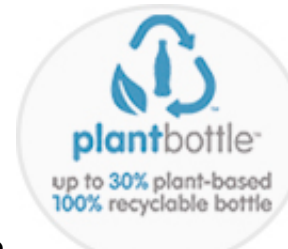

3.

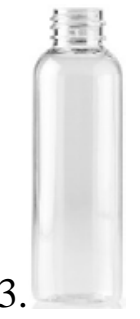

4.

Figure 4: Blue label (1), OnBottle information (2), Minimalistic form (3), Conventional form (4)

The minimalistic form and on-bottle information were the sustainable designs of the form and information according to the pre-test. For graphics the green label was the more sustainable variant, however in the rankings the neutral looking blue design was pointed out as most sustainable of the two which is therefore not as expected. This could be explained by the fact that the label contains nature imagery and shows more congruency with water, which can trigger a more natural feeling. According to the importance values in Table 2, graphics clearly matter the most (average of 44,462), followed by information (average of 29,809) and form (average of 25,729). Regarding the ranking on appeal and sustainability there is no significant difference between the importance values of information and form. The minimalistic form has the highest 
utility for these rankings as well as the ranking on buying intention, which are important subjects for purchase behaviour. For these reasons the combination of the blue label, on-bottle information and minimalistic form is identified as the profile with the highest utility. Similarly, the combination of the green label, on-label information and conventional form is identified as the profile with the lowest utility. The designs are shown in Figure 5.

According to the question including a price the combination of a blue label, on-label information and minimalistic form was chosen most (21 times), followed by a blue label, on-label information and conventional form (15 times) and a blue label, on-bottle information and minimalistic form (12 times). Buying intention thus seems to be greatest for the blue label, onlabel information and minimalistic form, which is not fully in line with the utility scores from the rankings. The blue label and minimalistic form also have the highest utility according to the rankings, whereas on-bottle information has a higher utility than on-label information.

1.

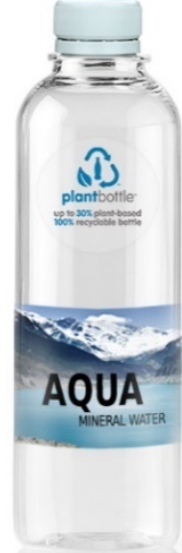

2.

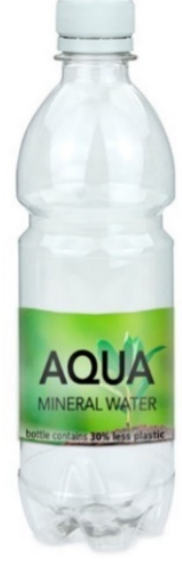

Figure 5: The designs with the highest utility (1) and the lowest utility (2).

This may be due to the fact that the bottles with on-bottle information were 14 cents more expensive than the ones with on-label information.

In the last question respondents had to allocate a total of 100 points to several attributes of a bottle of water according to importance. Price was seen as the most important attribute (mean of 27 points), followed by form/design of the bottle (mean of 21 points) and sustainability and recyclability (both a mean of 14 points). According to these results, the form and design of the bottle is an important feature as evaluated by consumers, but when judging bottles during the rankings the form was of lesser importance than graphics and information. This may be due to the assumption that consumers point out other aspects as important than the aspects that matter when making an actual choiche. The results of this study show that decisions made by consumers regarding the packaging are mostly based on graphics and to a lesser extent on information and form. Eventhough they think form is very important, the results of their actual judgements show otherwise. When product prices are included price seems only to have an influence on the informational feature whereas the graphics and form are chosen similar to the highest utility.

\subsection{Part two}

In total, 200 cups were served to customers and 96 of them gave their opinion about the bottles. It had not been possible to ask all 200 customers to give their opinion on the designs of the bottles, since some of them were in a hurry or only picked up a cup and moved on. The bottle with the lowest utility (2) was picked 18 times and the bottle with the highest utility (1) was picked 78 times (Figure 5). Thus, design 1 is also in favour as physical bottle in a realistic setting, 
according to our expectation. After execution of the test the cups and wrappers were counted and 136 cups were found back in the recycling bin and 15 in the conventional bin. The other cups could not be located and had presumably been thrown in another bin in the supermarket or had been taken outside the supermarket. This resulted in the following numbers, see Table 3. Most cups were thrown in PMD with many wrappers still attached. The plastic cups themselves were thus thrown away correctly in contrast to the wrappers. Near the end of the test the PMD compartment contained many cups and some were sticking out of the bin. Seeing other cups with wrappers in this compartment may have triggered following customers to throw their cup in there as well without removing the wrapper. Looking at the two variants of wrappers the orange version was found more in general and also has a slightly higher recycling rate as these were thrown more into paper waste, which is in contrast to what was expected.

Table 3: Results of the bin counting

\begin{tabular}{|l|l|l|l|l|l|l|l|l|}
\hline & \multicolumn{3}{|l|}{ Orange wrapper } & \multicolumn{2}{l|}{ Green wrapper } & \multicolumn{2}{l|}{ Cups } \\
\hline Waste stream & $\begin{array}{l}\text { Cup incl. } \\
\text { label }\end{array}$ & $\begin{array}{l}\text { Individual } \\
\text { label }\end{array}$ & Total & $\begin{array}{l}\text { Cup incl. } \\
\text { label }\end{array}$ & $\begin{array}{l}\text { Individual } \\
\text { label }\end{array}$ & Total & $\begin{array}{l}\text { Cup exc. } \\
\text { label }\end{array}$ & Total \\
\hline Paper & 0 & 14 & 14 & 2 & 8 & 10 & 6 & 8 \\
\hline PMD* & 30 & 17 & 47 & 30 & 13 & 43 & 58 & 118 \\
\hline Residual & 3 & 1 & 4 & 3 & 1 & 4 & 4 & 10 \\
\hline Conventional bin & 8 & 0 & 8 & 7 & 0 & 7 & 0 & 0 \\
\hline Total & 41 & 32 & 73 & 42 & 22 & 64 & 68 & 136 \\
\hline
\end{tabular}

*PMD = Plastic, Metal and Drink cartons

However, some wrappers fell off the cups and customers picked it up, after which they threw it into paper waste. It may be possible that by accident more orange wrappers fell off than green ones which explains why more orange wrappers were found in paper waste. It is also unclear if all the loose labels found in the waste were taken off by customers or if they had fallen off in the garbage bag due to movement and humidity. Therefore, the numbers of individual wrappers (Table 3) and consequently the number of wrappers removed by customers might be lower. We expect the low recycling rates of the green wrapper could be due to additional factors. Firstly, during the observation we noticed that some customers looked at the cup and label during the tasting but did not remove the wrapper afterwards. They seemed rather occupied with the tasting itself and may not have noticed the recycling cues. Other factors are expected to be due to the design of the wrappers. The text on the green wrapper is black which has a lower contrast than black text on an orange background. Furthermore, it may not have been clear enough to customers that the wrapper had to be taken off the cup, as there were no cues signalling that this had to be done, apart from the logo from the Waste Pointer. Moreover, the paper was very thin and might not have felt paper-like in contrast to thicker paper or cardboard. This can also explain why a few persons picked up wrappers which had fallen off and still threw it into PMD.

\section{Conclusions}

This paper aims to bridge the gap between packaging design and consumer behaviour during purchase and recycling of sustainable packaging. We conducted an empirical study to determine the influence of specific design elements of sustainable packaging on consumer behaviour. The results of the first study show that decisions made by consumers regarding the packaging are 
mostly based on graphics and to a lesser extent on information and form. Furthermore, a sustainable form and information regarding sustainability have a higher utility than a neutral form and information, which indicates that these cues are able to trigger a higher buying intention. In terms of graphics, it is important to maintain congruency with the product inside, however nature imagery and natural sights seem to have a positive influence on overall utility. In relation to purchase intention when prices are included, the results indicate that the design with the highest utility would be chosen in many cases. However, consumers seem less willing to pay more for an extra label containing information on packaging sustainability. According to the second study, the bottle with the highest utility is clearly more in favour than the bottle with the lowest utility, which amplifies the results of the first study. According to the results on recycling behaviour, it is unclear if recycling logos and a stimulating text have an impact on recycling intention of consumers. We recommend an additional test which is less task oriented and takes into account the factors regarding the design of the wrappers as discussed.

\section{Acknowledgements}

We would like to thank the Albert Heijn Thiemsbrug supermarket in Hengelo, The Netherlands for providing us space and materials to conduct our test.

\section{References}

Anonymous. (2013). Duurzaam Verpakken voor de Circulaire Economie. Retrieved from

Buelow, S., Lewis, H., \& Sonneveld, K. (2010). The role of labels in directing consumer packaging waste. Management of Environmental Quality: An International Journal, 21(2), 198-213. doi:doi:10.1108/14777831011025544

Crowe, H. (2003). De Nederlandse Verpakkingsstatistiek 2003. Gouda: Nederlands VerpakkingsCentrum.

Geiger, J., Ünal, A. B., Van der Werff, E., \& Steg, L. (forthcoming). The influence of biospheric values and packaging design on recycling behaviour.

Jerzyk, E. (2016). Design and Communication of Ecological Content on Sustainable Packaging in Young Consumers' Opinions. Journal of Food Products Marketing, 22(6), 707-716. doi:10.1080/10454446.2015.1121435

Lindh, H., Olsson, A., \& Williams, H. (2016). Consumer Perceptions of Food Packaging: Contributing to or Counteracting Environmentally Sustainable Development? Packaging Technology and Science, 29(1), 3-23. doi:10.1002/pts.2184

Magnier, L., \& Crie, D. (2015). Communicating packaging eco-friendliness An exploration of consumers' perceptions of eco-designed packaging. International Journal of Retail \& Distribution Management, 43(4-5), 350-+. doi:10.1108/ijrdm-04-2014-0048

Magnier, L., \& Schoormans, J. (2015). Consumer reactions to sustainable packaging: The interplay of visual appearance, verbal claim and environmental concern. Journal of $\begin{array}{llll}\text { Environmental } & \text { Psychology, 53(Supplement } & \text { C), }\end{array}$ doi:https://doi.org/10.1016/j.jenvp.2015.09.005

Nordin, N., \& Selke, S. (2010). Social aspect of sustainable packaging. Packaging Technology and Science, 23(6), 317-326. doi:10.1002/pts.899 
Pancer, E., McShane, L., \& Noseworthy, T. J. (2015). Isolated environmental cues and product efficacy penalties: The color green and eco-labels. Journal of Business Ethics, 143(1), 159-177.

QuadPackaging. (2018). Sustainable packaging and brand identity: understanding how sustainable messaging influences consumers decisions. Retrieved from

Rokka, J., \& Uusitalo, L. (2008). Preference for green packaging in consumer product choices Do consumers care? International Journal of Consumer Studies, 32(5), 516-525. doi:10.1111/j.1470-6431.2008.00710.x

Ruepert, A. M., Keizer, K., \& Steg, L. (2017). The relationship between Corporate Environmental Responsibility, employees' biospheric values and pro-environmental behaviour at work. Journal of Environmental Psychology, 54, 65-78.

Steenis, N. D., Van Herpen, E., van der Lans, I. A., Ligthart, T. N., \& van Trijp, H. C. M. (2017). Consumer response to packaging design: The role of packaging materials and graphics in sustainability perceptions and product evaluations. Journal of Cleaner Production, 162(Supplement C), 286-298. doi:https://doi.org/10.1016/j.jclepro.2017.06.036

Van Rompay, T. J., \& Pruyn, A. T. (2011). When visual product features speak the same language: Effects of shape - typeface congruence on brand perception and price expectations. Journal of Product Innovation Management, 28(4), 599-610.

Young, S. (2008). Packaging and the Environment: A Cross-Cultural Perspective. Design Management Review, 19(4), 42-48. doi:10.1111/j.1948-7169.2008.tb00140.x 